\title{
ANTROPOLOGÍA DEL MILENARISMO: EL PREMILENARISMO ENTRE LOS ADEVENTISTAS Y PENTECOSTALES EN LOS ESPACIOS FRONTERIZOS CHILENO-BOLIVIANOS*
}

\author{
The anthropology of Millenarianism: Pre-Millenarianism among Adventists \\ and Pentecostals in Chilean-Bolivian border spaces
}

\author{
Miguel Ángel Mansilla** \\ Universidad Arturo Prat \\ ORCID: 0000-0001-5684-0787
}

\author{
Sandra Leiva Gómez ${ }^{* * * *}$ \\ Universidad Arturo Prat \\ ORCID: 0000-0003-4883-6942
}

\section{Resumen}

El objetivo de este artículo es analizar las condiciones culturales y las propuestas teóricas del premilenarismo y sus usos como recursos por parte de las comunidades religiosas presentes en los espacios fronterizos chilenos y bolivianos. Para ello hemos dividido el artículo en tres partes: (i) Mitos milenarios en espacios (trans)andinos, (ii) Teorías sobre el milenarismo y (iii) El (pre)milenarismo en la frontera chileno-boliviana. De igual modo, este último apartado lo dividimos en tres partes, sobre el uso y transformación del premilenarismo por parte de las comunidades adventistas y pentecostales como recurso triple: social, político y simbólico, lo que rompe con el mito sobre el

\footnotetext{
* Este trabajo, es parte de los resultados del proyecto Fondecyt Regular 1180924 "La fe mueve fronteras. Comunidades evangélicas, movilidad circulatoria y resignificación étnica, nacional y religiosa de los indígenas andinos en las fronteras del norte de Chile con Perú y Bolivia”, financiado por la Agencia Nacional de Investigación y Desarrollo, ANID.
} 
premilenarismo concebido como huida y quietismo social. En consecuencia, se constituye en una creencia que acciona al creyente, no solo en la esperanza de la movilidad social en el más allá, sino en la posibilidad del cambio social en el más acá.

Palabras clave: adventistas, pentecostales, transfronterizo, premilenarismo, indígenas.

\begin{abstract}
The goal of this article is to analyze the cultural conditions and theoretical proposals of pre-Millenarianism and their uses as resources for some of the religious communities present in Chilean and Bolivian border spaces. We have divided the article into three parts: (I) Millenarianist myths in (cross)Andean spaces, (ii) theories on Millenarianism and (iii) (Pre)Millenarianism at the Chile-Bolivia border. The final section is divided into three sub-sections on the use and transformation of pre-Millenarianism by Adventist and Pentecostal communities as a triple resource: social, political and symbolic, which breaks with the myth of pre-Millenarianism conceived of as social flight and quietism. As a result, a belief is constituted that activates the believer in the hope of social mobility in Heaven and the possibility for social change on Earth.
\end{abstract}

Keywords: Adventists, Pentecostals, cross-border, pre-Millenarianism, indigenous.

\title{
Introducción
}

Los antropólogos han descrito distintos tipos de movimientos milenaristas, ${ }^{1}$ tales como los cultos de cargo de Melanesia de principios del

\footnotetext{
${ }^{1}$ El milenarismo es definido como un movimiento sociorreligioso, cuyo origen se explica así: "masas desarraigadas y desesperadas de la ciudad y del campo que viven en los márgenes de la sociedad. En sus inicios estos movimientos se difunden superando todo tipo de divisiones tribales y nacionales. En la práctica el impulso inicial se agota pronto y el movimiento acaba 
siglo XX (Harris, 1999; Worsley, 1980), la danza de los espíritus (Frigerio, 2000; Lanternari, 1965; Pereira de Queiroz, 1978), el movimiento de Antonio Conselheiro (Pereira de Queiroz, 1978), el mito del regreso del Emperador Durmiente en Perú (López-Baralt, 1989; Robins 1997;), o la tierra sin mal (Meliá, 1991; Worsley, 1980). Los movimientos milenaristas siempre conciben la salvación como un hecho colectivo, inminente, total y milagroso (Barabas, 2002; Cohn, 1997; López, 1990. Ante las condiciones de desesperanza frente a los cambios, lucha social y política sin resultados, algunos grupos se hacen parte de movimientos de protestas y propuestas simbólicas. En este sentido, la utopía milenarista es una posibilidad a la que recurren los oprimidos, porque no tienen nada que perder y un mundo por conquistar, cifrando sus esperanzas en que el estado de cosas actual se invertirá (Monsiváis, 1986). La esperanza milenarista es activa y no pasiva, como toda esperanza. Hay acción. Los creyentes se movilizan para que los cambios sucedan. Puede que se autodefinan como apolíticos, pero la crítica al mundo, a la sociedad y al contexto social, es una crítica política. Pueden ser definidos como movimientos espiritualistas de escapes, pero, al predicar y atraer a otros al movimiento no sólo creen en la esperanza, sino que también activan la esperanza.

El milenarismo se compone de consuelo y esperanza, lo que se engarza con el mito. Es decir, el milenarismo fue realidad en un tiempo primigenio, en un pasado mítico, en cuya sociedad los seres humanos eran iguales y libres. Pero un acontecimiento cruel rompió ese tiempo y espacio idílico. Ese tiempo y espacio dorado será real nuevamente, solo que ahora será para los escogidos, para los oprimidos, excluidos, humillados y despreciados de la sociedad. En efecto, el milenio será un acontecimiento para un futuro cercano; luego de pasar la prueba final, llegará una época de igualdad y bienestar colectivo, lo cual explica por qué ha sido una ideología predilecta de los oprimidos y explotados

por ser una institución más entre otras, con frecuencia más militante y fanática que las demás, debido a que llega a creerse el depositario único de las verdades humanas universales" (Turner, 1988, p. 118). 
(López, 1990). Esta creencia no solo genera esperanza, sino también consuelo frente a la orfandad social y política.

Encontramos una sociología de la esperanza (Desroche, 1976), una filosofía de la esperanza (Bloch, 2004), una psicología de la esperanza (From, 1970), una pedagogía de la esperanza (Freire, 1992), pero no hay hallazgos de una disciplina dedicada al consuelo. No hay una sociología ni una antropología del consuelo, pese a que la palabra consuelo lleva un prefijo que denota reunión, junto a otros, y que implica comunidad: literalmente significa consolari, de con (reunión, cooperación, unión) y solari (alivio, calma, atenuar). De este modo, el consuelo es un alivio cooperativo. Las personas que se unen a grupos religioso (pre)milenaristas, como los adventistas y los pentecostales, no lo hacen solo por la esperanza, sino también por el consuelo, el que genera la solidaridad comunitaria en el presente. Ese consuelo comunitario activa la esperanza.

No obstante, el consuelo es concebido o imaginado como "opio", un concepto enajenante y negado; invisibilizado y excluido de las reflexiones científicas sociales. En consecuencia, el milenarismo en realidad es un concepto que relaciona lo temporal: pasado (mito), presente (consuelo) y futuro (esperanza). Excluir el consuelo del análisis del milenarismo es negarle su rol terapéutico y revitalizador para las personas, grupos o comunidades que sufren y que ven en el milenarismo un alivio a las angustias, agobios y penas frente a las condiciones sociales degradantes y miserables de la actualidad. Hoy por hoy, la pobreza, la exclusión social y la discriminación, condiciones de vidas lastimosas, se trastocan ante los mensajes que circulan en la televisión e internet, donde se muestran mundos y sociedades prósperas que aumentan las angustias y frustraciones de quienes constatan que no es posible salir de la miseria ni mejorar las condiciones de vida solo trabajando. El trabajo empobrece. Las condiciones sociales enferman. De este modo, el premilenarismo predicado y cantado por los adventistas y pentecostales en las fronteras chileno-bolivianas no es una fuga de la realidad, sino que aporta recursos sociales, políticos, así como un sentido de justicia, que revitalizan y 
movilizan a los creyentes andinos. Estos encuentran sentido y significado en ese mensaje que contrasta con el sinsentido y las aporías sociales de la realidad a la que están expuestos.

Lo que une a adventistas y pentecostales es que son premilenaristas. Lo que los diferencia es que los adventistas son "futuristas históricos" y los pentecostales son “futuristas dispensacionalistas". Al respecto, D’Epinay (1968) y Tennekes (1985) señalan que el premilenarismo es una utopía de los oprimidos y de los explotados; una visión desesperanzada y derrotista sobre la sociedad. Para Frigerio (2000)

es una idea de que los humanos poco podemos hacer para adelantar o retrasar la segunda llegada de Cristo y la batalla final. Es uno de los motivos de su apoliticismo y retracción de la sociedad, así como su énfasis en la conversión y la salvación individual (p. 2).

Es, justamente, lo que a su vez caracteriza tanto al adventismo como a la Iglesia Evangélica Pentecostal, asentados en la zona fronteriza: su apoliticismo declarado y su énfasis en la evangelización y conversión. No obstante, la gran diferencia está en la relevancia que el adventismo le asigna a la educación y a la salud como servicio al prójimo, sin que dicho servicio sea a cambio de conversión. En tanto los pentecostales no se preocupan de dichos servicios, destacan que para ello está el rol del Espíritu Santo: sanar y educar. Si hay enfermos se ora, intercede o impone manos por ellos para que sean sanados; para la educación, están las escuelas dominicales. Los primeros brindan un servicio a toda la comunidad; los segundos: solo a la comunidad de salvados. Pero, aun así, ambos crecen en la zona altiplánica transfronteriza chilenoboliviana.

En medio de un contexto con un clima desértico: días muy calurosos, noches muy frías y con viviendas precarias; en un contexto de trabajo muy duro: levantarse a trabajar, una tierra que no es suya sino arrendada, en donde las condiciones climáticas parecieran ser que confabulan para impedir que la tierra sea productiva. Cuando la tierra es productiva, entonces el mercado baja 
las ganancias de los productos agrícolas. De este modo, los recursos bíblicos ayudan a interpretar que el diablo y los demonios se encargan de generar dificultades y obstáculos; un complot invisible, pero no invencible contra el creyente. La fuente de esa conspiración universal es el diablo. Para el funcionalismo psicologista, esto es paranoia religiosa. Pero para los creyentes andinos es pronoia, en tanto la Biblia y Dios actúan revirtiendo lo malo, lo negativo y la desgracia en bien y para bien de los creyentes. Para ellos hay un verso bíblico: "sabemos que para los que aman a Dios, todas las cosas cooperan para bien, esto es, para los que son llamados conforme a su propósito" (Rom. $8: 28)$. Es en este contexto donde las creencias premilenaristas persisten del lado de Bolivia, muy activos en las prédicas, cantos y ritos. Del lado de Chile, permanecen muy vivos en los cantos, pero disminuidos en las prédicas y ritos. Del lado de Bolivia, el premilenarismo es ritualizado; del lado de Chile es estilizado. En efecto, cuando los creyentes transitan de un lado a otro de la frontera se encuentran con la creencia premilenarista.

Los estudios sobre premilenarismo han sido bastante desarrolladas del lado de Bolivia y de Perú, pero no de Chile, ni mucho menos como creencia ni práctica transfronteriza. Para Albó (2005), el (pre)milenarismo

se trata de un alistamiento porque Dios puede llegar en cualquier momento, con la muerte y el juicio a cada uno. Pero en muchos de los congregados esta venida inminente se tomaba, sin duda, como algo verdaderamente real, y pasó a ser uno de los elementos centrales de la convivencia. (Albó, 2005, p. 263).

En la misma línea, Rivière (1988) destaca que la identidad del pentecostalismo se ve reforzada por una certeza compartida: la inminencia del fin de los tiempos. Los pastores comentan constantemente los versículos de la Biblia que mencionan los signos que anuncian el fin de los tiempos y que cualquier persona puede experimentar en la vida cotidiana: terremotos, malas cosechas, sequías, disputas y divisiones (Rivière, 1988, 2004). Del lado peruano encontramos a Marzal (1989), refiriéndose al pentecostalismo peruano, al destacar que "el énfasis de un escatalogismo inminente, conduce a cierta 
revitalización de la tarea de transformar el mundo, debido a la concepción insistente de la malignidad del mundo" (1989, p. 427).

¿Por qué el premilenarismo adventista y pentecostal predicado $\mathrm{y}$ cantado, ritualizado y estilizado, es atractivo para los andinos que viven y transitan por los espacios transfronterizos chilenos y bolivianos? No es el premilenarismo lo que atrae a los andinos, sino las prácticas comunitarias que se urden y se tejen en torno a las creencias premilenaristas. Tanto los adventistas como los pentecostales disponen de templos en los espacios fronterizos tanto del lado chileno como del boliviano, que se constituyen en redes y corredores transfronterizos entre las personas bolivianas y chilenas. Por una parte, cuando estas comunidades llevan a cabo sus ritualidades, según las creencias premilenaristas, como los ayunos y retiros, generalmente lo hacen en espacios andinos, principalmente cerros y desiertos, y en espacios fronterizos que sirven de espacios liminales. Por otra parte, ese tiempo de comunidad religiosa se constituye en comunidad étnica que se traduce en vigilias, retiros, paseos congregacionales. Son tiempos y espacios en donde se habla y canta en aymara. Son tiempos y espacios que son dirigidos por líderes indígenas. Allí encuentran un lugar los adultos y adultos mayores aymaras para rememorar y vivir la comunidad indígena en crisis para ellos, pero que es revitalizada en la comunidad religiosa.

Además, tanto adventistas como pentecostales disponen de recursos comunitarios, tales como hospedajes para las personas que van y vienen de un lado de la frontera a otro. Disponen de ayudas alimentarias, ropas u ofrendas para los feligreses necesitados. Disponen de grupos de oración, intercesión y de acompañamiento para las personas y familias que sufren de enfermedades y pérdidas en la agricultura. En el marco de la disolución de las comunidades tradicionales, las comunidades evangélicas actúan como comunidades sustitutas de tránsito $\mathrm{y}$, en algunos casos, de refugio para quienes se mueven por los espacios de fronteras por razones económicas, laborales o familiares. Por su atributo transnacional y composición interétnica, se advierten en las comunidades evangélicas redes de movilidad y circulación en el espacio de 
fronteras. En síntesis, por su carácter misional y comunitario transnacional, las comunidades evangélicas participan activamente en los circuitos de movilidad en el área de fronteras nacionales y étnicas. De este modo, el tiempo y el espacio premilenial adquiere asidero histórico y personal concreto para aquellos que lo necesitan y la plausibilidad de una proyección de un futuro real para revivir dichas comunidades.

En consecuencia, el objetivo de este artículo es analizar las condiciones culturales y las propuestas teóricas del premilenarismo y sus usos como recursos por parte de las comunidades religiosas presentes en los espacios fronterizos chilenos y bolivianos.

\section{Mitos milenarios en espacios (trans)andinos}

Uno de los grupos étnicos más conocidos por la utopía y la práctica milenarista es el de los guaraníes, quienes desde antes de la colonización han estado buscando un lugar que les ha sido revelado por sus antepasados, donde la gente vive libre de dolor y de sufrimiento. Lo llaman "la Tierra sin mal" (Meliá, 1991; Morales, 1980; Pereira de Queiroz, 1978. Esta tierra no es un sueño, sino una tierra real adonde los guaraníes emigran una y otra vez para reiniciar el proceso de asentamiento. Esa identidad migratoria permanece hasta hoy (Watson, Corry y Pearce, 2000). El fracaso en la búsqueda del paraíso terreno para algunos líderes religiosos guaraníes era interpretado como la mala aplicación de los ritos; es decir, respondía al sacrilegio de los mismos nativos (Lanternari, 1965; Meliá, 1991). En efecto, no ponen en cuestión las creencias, sino el rito y las condiciones del rito que se vuelven ineficaces. En tanto, el discurso de la búsqueda de la "Tierra sin mal" hiberna hasta que aparezca una crisis y algún líder carismático que revitalice aquella búsqueda (Meliá, 1991). Este mito milenario alguna vez fue un motor que vitalizó a los guaraníes para que emigraran de un lugar y de una tierra ya desgastada e infértil a otra. Transitaron durante años de un espacio y tiempo mitificado a otro, pero esto fue obstruido por la delimitación de fronteras de los Estados nacionales (Brasil, 
Bolivia, Uruguay y Paraguay). Así, los mitos servían para movilizar a las nuevas generaciones y encontrar los nuevos líderes que guiaran al pueblo hacia esa tierra anhelada.

En Argentina también han existido los movimientos milenaristas (Bou, 1997; Frigerio, 2000; Lynch, 2001; Terán, 2000). Hubo movimientos mesiánicos-milenaristas en 1872, 1904 y 1933. Gerónimo de Solané, autoproclamado enviado de Dios, llegó a la zona de Tandil y con su prédica mesiánica exacerbó el odio contra los inmigrantes. El profeta era apodado Tata Dios o Médico Dios. Tandil era por entonces un pequeño poblado que había sido fundado en 1823, del que parte de sus habitantes eran extranjeros, principalmente de origen europeo. Los inmigrantes de la vieja Europa, quienes a su llegada utilizaban herramientas como el arado y la monta, pronto comenzaron a crear y utilizar nuevas técnicas, desconocidas en estas regiones: cruzaban las razas del ganado vacuno y lanar, y el comercio se transformó en una actividad próspera entre los inmigrantes. Esto sembró el malestar del poblado, y con la llegada del Tata Dios comenzaron a tener reuniones periódicas con el profeta. No solo Solané y sus seguidores guardaban resentimiento en contra de los inmigrantes europeos, sino también ciertos estancieros y peones criollos. Existía en la sociedad un germen subyacente que Tata Dios y su gente llevaron al paroxismo (Lynch, 2001; Macagno, 2002). Este milenarismo se gestó a través del miedo al inmigrante y el deseo de sus posesiones, lo que indujo a peones criollos a levantarse contra los inmigrantes considerados como enemigos (Frigerio, 2000).

En este caso, los milenaristas y sus mesías defienden una díada: patria y religión, mientras que los inmigrantes serían los enemigos que hay que expulsar porque son lo opuesto: extranjero-gringo y ateos-irreligiosos (Frigerio, 2000). No son solo las condiciones, sino también la conciencia y creencia en la transformación de esas posibilidades lo que genera una revitalización de los mitos y activación de los ritos, haciéndose visible la dicotomía nosotros/enemigos, presente/futuro, indios/blancos (Frigerio, 2000). Tanto la explotación como el hambre es lo que induce a creer en el milenarismo como 
una forma de resolver la carestía que ya no satisface las tierras expropiadas por los blancos y el Estado. Asimismo, los sueños son los medios por los cuales se animan y fortalecen las creencias milenaristas. A "través de los sueños se revela el que será el líder religioso encomendándole acciones para la liberación de la humanidad, pero también se sueñan los diagnósticos, las curas y las prácticas terapéuticas" (Barabas, 2002, p. 23).

En Brasil, los personajes mesiánicos son muy particulares, pues se cristalizan en torno a individuos reales, como el padre Cicero o el fraile João María, que han sido los más estudiados (Bastide, 1973; Lanternari, 1965; Morales, 1980; Pereira de Queiroz, 1978. Entre las características de estos mesías, está el que a sus ciudades mesiánicas las apellidaban con nombres bíblicos de origen judaico como Nueva Jerusalén, y no con los nombres de ciudades católicas como Roma, porque estas últimas las asociaban al colonialismo (Pereira de Queiroz, 1969). Estos son símbolos muy relevantes porque, al igual que Jesús, estos mesías se identifican con los pobres, los explotados y los oprimidos, a diferencia de los líderes religiosos católicos y protestantes, a los que ellos criticaban constantemente porque vivían en comodidades y en opulencias, mientras el pueblo a los que ellos enseñaban y dirigían, sobrevivían en la miseria.

Los aspectos milenarios de los levantamientos en Perú y Bolivia han mostrado que las expectativas indígenas de progreso en las regiones quechua y aymara encontraron fuerte expresión en la rebelión regional, que condenaba y quería eliminar el sistema sociopolítico económico español. Esto grafica que los movimientos milenaristas buscan el retorno de las costumbres primigenias y el dominio nativo. Todos "los líderes utilizaron la rica herencia mesiánica de la región andina, para forjar una ideología milenaria que inspiró finalmente una respuesta masiva" (Robins, 1997, p. 103). El milenarismo fue una manifestación muy temprana en la colonización del Perú, como es el caso de

el Taki Onqoy (1565) [que fue] el primer culto de crisis que se conoce en la historia moderna del Perú. Su temprana aparición limita enormemente la influencia del cristianismo, convirtiéndolo en un fenómeno casi 
exclusivamente indígena de raíz prehispánica. Las divinidades que los españoles habían destruido resucitaron y se prestaron a dar batalla al dios cristiano. (De La Torre, 2004, p. 14).

La llegada del milenio implica un combate cosmológico, una lucha de dioses: los dioses invasores y los dioses de la Tierra. Para expulsar a los invasores hay que expulsar a los dioses estertores. Al respecto, De La Torre (2004) marca

la revuelta de Juan Santos Atahualpa (1741-1751), que apareció en mayo de 1742, cuando un indígena se autoproclamó Inca y le siguió mucha gente de la montaña y pidió el apoyo de todas las etnias de las selvas llamándolas a la batalla final contra el enemigo, los viracochas. Su ánimo era cobrar la corona que le había quitado Pizarro y los demás españoles, matando a su padre y enviando su cabeza a España. (p. 14).

De igual modo encontramos experiencias milenaristas en Chile con el jesuita chileno Manuel Lacunza (1731-1801), quien señalaba que antes del final de la historia se esperaba la venida del Mesías Jesucristo para establecer su reino en la Tierra, donde se produciría el pleno cumplimiento de la justicia, paz, libertad y fraternidad que Dios había prometido a la humanidad. Para Lacunza, el reino mesiánico-quialístico se iniciaba con la transformación de la naturaleza humana, que tiene como finalidad la perfección humana edénica y paradisiaca, destruida por el pecado. Este mundo milenial no es algo meramente mejor que el presente, sino que es un mundo nuevo en lo moral, lo físico y material. Este neomundo termina con siglos de pecado, y participarán de esta plenitud eterna, tras la resurrección universal, los creyentes bienaventurados que gozarán juntos eternamente de la contemplación del mundo transfigurado y en comunión con Dios, como era la idea primigenia (Góngora, 1980; Martínez, 1990; Parra, 2003; Rojas, 2001). Lacunza no era indígena, pero sí excluido y exiliado político, en tanto era un jesuita que había sido expulsado de la tierra nueva, de la tierra del milenio cristiano imperialista y colonizador mediado por la Iglesia católica. 
Para Lacunza, la historia es vista no como progreso, sino como decadencia. Es una concepción histórica con tres grandes momentos: la Creación, la Redención y el Apocalipsis. En la idea milenarista de Lacunza hay un doble escathon, uno es el que pone fin a la historia y un segundo que comienza con la Parusía. En el milenio la Iglesia no tendrá sentido porque cuando el orden espiritual se percibe por una visión o por contemplación directa, no tiene sentido el poder mediador de la Iglesia, ni la prédica, ni los sacramentos. Es el fin de la Iglesia jerárquica y clerical. (Rojas, 2001, p. 32).

El milenarismo también lo encontramos entre los mapuches, entre quienes tal creencia es una influencia cristiana que se vivencia, además, bajo las condiciones de destierro y de avallasamiento impuestas por los conquistadores en sus propias tierras:

Ellos desean vivir en el тари у en el жепири (cielo), como lo hacían sus antepasados: libres de opresión huinca, con abundancia de toda clase de animales y sembrados, sin enfermedades y con kullin (plata, ganado) para sus intercambios matrimoniales, en definitiva, una vida más auténtica y plena, acorde con el admapu. Si este estado anteriormente fue posible gracias a la guerra y al apoyo dado por las divinidades ancestrales, la derrota militar, la ocupación de sus tierras y la opresión llevaron a los mapuches y a sus profetas, en la primera mitad del siglo $\mathrm{XX}$, a desear que sus divinidades (incluso a las que consideraban como maléficas) hicieran lo que ellos ya no podían hacer. (Foerster, 1993, p. 141).

En la cultura mapuche-huilliche existe un sustrato milenarista que consiste en la eliminación del "huinca" como condición de posibilidad de la superación de la mala condición del mapuche (Vergara, Foerster y Gundermann, 2005).

El milenarismo en los Andes también se manifiesta a través de los líderes independentistas (esperanza propia de cada grupo colonizado que adquiere conciencia de emancipación) y posteriormente de los colonizadores de tierras baldías, procedentes de Europa, ya sea de Alemania, Italia o España, 
quienes ven en estas tierras la posibilidad de construir una tierra nueva y un cielo nuevo para ellos y sus descendientes. Milenarismo que, posteriormente, también estará presente en las distintas revoluciones a lo largo del siglo XIX y $\mathrm{XX}$, y manifiesto entre los dictadores y también en los líderes del retorno democrático: cada uno, cada tipo de milenarismo, manifiesta un enemigo; una lucha y un retorno de un tiempo de paz, seguridad y orden.

Hay que pensar que justamente en este espacio transandino (Bolivia, Chile, Argentina y Perú, pero también Brasil) se movilizan y migran los andinos, y es donde disponen de grandes comunidades aymaras y quechuas, en menor medida. Es el lugar también donde encontramos bien extendidas y situadas las comunidades adventistas y también donde están presente los pentecostales de la Iglesia Evangélica Pentecostal (con excepción de Brasil). En estos espacios culturales es donde han emergido los distintos tipos de milenarismo. Es aquí donde la utopía milenarista no desaparece de la cultura, sino que se simboliza y ritualiza. Es ahí donde se sitúan los movimientos premilenaristas, entre ellos adventistas y pentecostales, que emergen y se encarnan en los sectores marginales e indígenas; en donde se encuentran comunidades religiosas y comunidades indígenas en torno a la esperanza milenarista.

\section{Teorías sobre el milenarismo}

Para ahondar en lo antes descrito, podemos encontrar cuatro teorías sobre el fenómeno milenarista (López-Baralt, 1989): de la privación, psicologista, difusionista y tensionista.

La teoría de la privación es la más representativa de los autores de influencia marxista, entre los cuales encontramos a Balandier (1990), Bastide (1973), Hobsbawm (2003), Pereira de Queiroz (1978), Lanternari (1965), Robins (1997) y Worsley (1980). Aunque no podemos encasillar a estos autores solo en la postura del marxismo, sabemos que "el enfoque marxista considera como preponderante en la aparición de estos movimientos, la opresión y la 
explotación socioeconómica de un grupo sobre otro y asigna a estos movimientos una naturaleza revolucionaria" (Ullán de la Rosa, 2000, p. 18). Por ello el milenarismo se constituye en una espera y una búsqueda "en el estruendo del fin de los tiempos, (...) creencia que delega el sentido de la vida en un desenlace universal próximo, [y] es una de las manifestaciones más extrema y difundida de la cultura de la marginalidad" (Monsiváis, 1986, p. 211). Por su parte, Balandier destaca que el mesianismo

funciona como forma de resistencia opuesta por los pueblos colonizados a la dominación y explotación que les hacen sufrir los colonizadores, por ello siempre que el camino de la resistencia política se encuentre obstruido y no haya más senda que la religiosa para dar el paso a la protesta, el mesianismo será una posibilidad. (Balandier cit. en Bastide, 1973, p. 293).

Los representantes teóricos de esta corriente representan a los milenarismos con características similares. Los conciben como movimientos de los desheredados, movilizados por el profetismo (individual o grupal), que anuncian la inminencia del fin del mundo por un cataclismo que lo destruirá todo, tiempo en que los oprimidos, creyentes del movimiento, serán redimidos y los opresores serán destruidos o se transformarán en oprimidos; es decir, se producirá una inversión de la realidad. Esta revolución social será llevada a cabo por un redentor divino que satisfacerá todas las necesidades de los oprimidos, y será el comienzo de un reinado de bienaventuranza eterna. Mientras tanto hay que prepararse para el final, con distintos sacrificios y ritos religiosos, así como pregonando este futuro reinado del bien. A veces esta llegada es tan anhelada, esperada y buscada que los oprimidos se esfuerzan en apurar el fenómeno renunciando al trabajo y a sus escasas propiedades. Es lo que ha sucedido con el pentecostalismo cuando está vinculado a una variable étnica, algo que Albó (2005) describió en una comunidad pentecostal guaraní en Bolivia. Algunos entrevistados por él decían que el arrebatamiento era tan inminente que había que deshacerse de lo poco que tenían: "Ya teníamos que 
irnos al cielo y entonces empezamos a botar nuestro dinero y nuestros relojes" (Albó 2005, p. 264).

Respecto de la teoría psicologista, Barabas (2002) señala que "en un congreso realizado en Chicago en 1960, los especialistas rechazaron explícitamente las concepciones marcadamente psicologistas, dando mayor énfasis a los conceptos de privación social y crisis sociocultural como causales primarias de los movimientos sociorreligiosos" (p. 52). El principal exponente de la hipótesis sicológica es Norman Cohn (1997), quien condiciona el desarrollo del milenarismo a la existencia de una visión del mundo religiosa tradicional, que promete una era futura de bienaventuranza para el creyente. Cualquier ansiedad o humillación insólita que no pueda sobrellevarse recurriendo a una rutina institucionalizada, intensifica el latente anhelo humano de salvarse de una vez del sufrimiento, lo que proporciona la oportunidad perfecta para el surgimiento de un profeta. Este "elegido se convierte en el portador de la nueva salvación colectiva, apoyándose en la promesa de eterna bienaventuranza, presente ya en la tradición popular" (Cohn, 1997 p. 42). El trabajo de Cohn es uno de los mejores estudios sobre movimientos milenaristas desde la historia, aunque solamente restringido a Europa, específicamente a Alemania y Francia. No obstante, Barabas (2002) es una gran crítica de la postura que Cohn asume frente a tales movimientos como "explicaciones psicológicas descontextualizadas y etnocéntricas que le llevan a calificar a los milenarismos y mesianismos de fantasías paranoides colectivas" (Barabas, 2002, p. 53). No obstante, fuera de los prejuicios de las descripciones psicologistas de Cohn, se advierte en las manifestaciones premilenaristas de los adventistas y pentecostales en los espacios transfronterizos de Chile y Bolivia, una interpretación psicoantropológica, pero, sin atribuir prejuicios paranoicos.

En un segundo grupo identificamos a Bastide (1973), Desroche (1976) y Pereira de Queiroz (1978) (entre los más conocidos), quienes apuntan a una posición psicológica, destacando elementos como la frustración social, la anomia, la desestructuración de un viejo orden que induce a la pérdida de identidad social o étnica y la existencia de un grupo que posea una mitología 
apropiada (Ullán de la Rosa, 2000). Dado que la transformación ha sido rápida y profunda, determinados grupos se encuentran atravesando una grave crisis social que además se constituye en una crisis de sentido, de futuro y de certidumbre, en la que las viejas deidades han perdido poder; y las nuevas creencias tampoco producen plausibilidad en los grupos en crisis. De igual modo, se ponen en cuestión las creencias de los grupos opresores y explotadores. En este contexto aparecen nuevos discursos que en realidad son viejos discursos revitalizados, que movilizan a los oprimidos hacia creencias de que la situación actual cambiará por intermediación de un héroe redentor. Por consiguiente, la situación actual es necesaria y transitoria, pero se acerca un mañana glorioso y sublime en donde los oprimidos gobernarán. Estas creencias permiten a los milenaristas soportar la explotación con resignación, esperar un mañana mejor, pero, mientras tanto, también se generan otras posibilidades paralelas en donde la sociedad mejora y las creencias mileniales tienden a disminuir o soterrarse.

Esto también puede ser aplicable a los espacios transfronterizos chilenoboliviano, en tanto, por ejemplo, la revolución de 1952 en Bolivia no mejoró las condiciones sociales ni económicas de los indígenas; por el contrario, su identidad étnica y cultural fue reducida a campesinos. Mientras el catolicismo era la religión coligada a la oligarquía y a la burguesía dominante, emergieron en el contexto cultural los adventistas y los pentecostales: los primeros con su sistema de salud y educación dirigido a los indígenas (Ströbele-Gregor, 1989), y los pentecostales con su propuesta comunitaria con afinidad cultural con las comunidades andinas. Ambas comunidades religiosas comenzaron a ser lideradas por indígenas, tanto del lado chileno como del boliviano.

La teoría tensionista explica que las condiciones de explotación y miseria generan o producen las condiciones de revolución social o simbólica. Los "movimientos milenaristas surgen entre las masas desarraigadas y desesperadas de la ciudad y el campo, empujadas a vivir en los márgenes de las ciudades" (Turner, 1988, p. 118). Esto significa que son las mismas condiciones las que generan las distintas condiciones de milenarismo existentes, tanto en la 
historia como en diferentes partes del mundo, durante el siglo $\mathrm{XX}$, sin importar que sean o no cristianas. La "espera o búsqueda de un nuevo milenio surge en la historia de situaciones críticas extraordinarias. Surge en el desamparo, la inseguridad, el sentirse abandonado por alguien que ha retirado su apoyo y le condena al propio campo del valimiento" (Zea, 1986, p. 35).

El problema que presenta esta postura teórica es que se muestra como una autoignición, es decir, que las condiciones por sí mismas darían lugar a creencias milenaristas, pero la pregunta que nace es ¿por qué ante las mismas condiciones de pobreza, miseria y explotación, no todos se persuaden con las creencias milenaristas? En este plano podría tener sentido la postura psicológica, en tanto que aquellos a los cuales afecta mayormente la frustración y la anomia son propicios para tales creencias. Incluso aquellos que creen se constituyen en heraldos y profetas del milenio, para quienes

la salvación anhelada se representa y espera como una transformación completa de la que se beneficiarán todos los fieles en tanto que miembros de un grupo religioso. La salvación o redención se exterioriza como una utopía, una salvación inminente que conduce a una espera tensa, porque lo que llega es el futuro definitivo. (Osorio, 2004 p. 6).

¿Quiénes son los que se convierten o se han convertido, primero a los adventistas, y luego a los pentecostales? Son aquellos que se sienten excluidos o marginados de sus comunidades étnicas o no reciben la suficiente ayuda ante una crisis de vida, como las enfermedades, el desempleo o una crisis familiar grave. Sin embargo, necesitan de un conocido que los lleve a la comunidad religiosa. Sirven como de madrina o padrino para acompañarlos e integrarlos a la comunidad religiosa. Quienes se han adherido a los adventistas o pentecostales se sienten que son alguien en la comunidad, y luego, paulatinamente, se integran a la comunidad religiosa, primero a través de los distintos ritos y más tarde asumiendo roles.

Los postulados de la teoría difusionista apuntan a la idea de que las concepciones nacen en áreas culturales de civilización primigenia. En su postura más actualizada se refiere a préstamos culturales como resultado 
inevitable de la transferencia de información entre diferentes grupos sociales. Esta postura teórica tiene como finalidad buscar una explicación histórica sobre semejanzas existentes entre culturas particulares (Marzal, 1989. De alguna manera, el pueblo judío ha sido el grupo que en distintas épocas produjo y revitalizó creencias milenarias. Estas creencias las heredaron los oprimidos del Imperio romano, convertidos al cristianismo, donde es posible encontrar un terreno fértil para hacer florecer estas ideas traspasadas desde la Biblia. Estas concepciones han florecido una y otra vez en los distintos grupos oprimidos, toda vez que la Biblia ha llegado a las manos de aquellos, sobre todo desde el protestantismo y posteriormente desde el pentecostalismo, religiones del libro, las que incentivan la hermenéutica individual y presentan un Cristo como Mesías, sufriente, explotado y oprimido, que se rebela contra los opresores y se identifica con todo aquel que vive en las mismas condiciones, sin importar raza o cultura. Por ello, América Latina y África han sido terrenos fértiles en donde han aparecido los milenarismos, sobre todo en el siglo XX. Por lo tanto

la utopía aporta la imagen del mundo nuevo, pintado con tales colores que despertaban el deseo de vivir en él. La idea del milenio contempla toda la historia humana desde el punto de vista del futuro. El milenio cristiano ve la apertura hacia algo radicalmente nuevo. (Kumar, 2000, p. 251).

En consecuencia, sin ser eclécticos extremos, creemos que las cuatro posturas pueden ser aplicables para entender los premilenarismos adventista y pentecostal en la frontera chilena- boliviana. Aunque la teoría de la privación hoy nos parece un tanto anacrónica, pues se entiende como "la ausencia de bienes en relación con un grupo de referencia. Un individuo o una familia experimentan 'privación relativa' cuando carecen de bienes comunes en otros individuos y familias del entorno social" (Izcara, 2007 p. 14). Esto se puede advertir cuando en la televisión o en internet se muestran estilos de vidas prósperas que, según los postulados de ideólogos del neoliberalismo, serían fruto del valor del trabajo y del esfuerzo; no obstante, lo anterior contrasta con las personas integrantes de estas comunidades andinas, quienes se esfuerzan y 
trabajan desde muy temprano hasta muy tarde y no solo no logran salir de la pobreza y la miseria, sino que al transitar hacia al lado de la frontera chilena, encuentran lo mismo: trabajo y esfuerzo sin posibilidades de movilidad social. A eso hay que sumarle los prejuicios, desprecios y discriminaciones que empeoran las condiciones sociales, aumentando la desesperanza de este grupo social.

La teoría psicologista es aplicable, en tanto y en cuanto las creencias adventistas y pentecostales manifestaban propensiones a la convicción de una vida de bienaventuranza en conjunto con situaciones de frustraciones, angustia, precariedad y desencanto frente al mundo y al futuro. No veían ninguna posibilidad de que la sociedad chilena o boliviana les presentara posibilidad de mejoramiento por las vías de las instituciones tradicionales, como la política, la educación o la religión tradicional; todo lo contrario, las habían empeorado: lo único posible era creer y buscar las satisfacciones diferidas.

La teoría difusionista es tremendamente eficiente para explicarnos por qué los adventistas y pentecostales son ávidos creyentes del milenarismo, sin necesidad de vínculos con otros grupos. El énfasis en el estudio bíblico individual y en una hermenéutica literalista es lo que induce a los pentecostales y adventistas a creer en verdades bíblicas como acontecimientos históricos, sumado a que estas verdades religiosas son confirmadas con las experiencias místicas: sueños, visiones y revelaciones, para los pentecostales, junto con evidencias naturales y sociales de parte de los adventistas, las que son interpretadas en clave apocalíptica, tales como guerras mundiales, crisis económicas, golpes militares, hambrunas, guerras civiles. Sobre todo, la concepción del Estado de Israel, como "el reloj de Dios", los incentiva a creer en un (pre)milenarismo inminente.

Por último, la teoría tensionista nos sirve porque el siglo $\mathrm{XX}$ significó para América Latina una tensión constante entre campo y ciudad; sociedad tradicional y modernización; oligarquía-burguesía y proletariado; ideología comunista e ideología capitalista; intolerancia y competencia religiosa; además de mesianismos políticos que prometían mejorar las condiciones de hambre, 
enfermedades, viviendas y trabajo de los grupos desarraigados, lo que no se logró hasta fines del siglo XX. Esta teoría es posible utilizarla bajo una dimensión más economicista. Sea como fuere, la teoría tensionista puede adecuarse a los estudios del pentecostalismo y el adventismo en condiciones de pobreza, pero sobre todo para abordar la concepción pesimista del trabajo como factor de movilidad social. Esto no solo lo podemos encontrar en los cultos adventistas y pentecostales del lado de Bolivia, sino también en los espacios de los valles de Arica, en donde hay numerosos templos adventistas con población aymara migrante desde Bolivia. Para que el milenarismo se revitalice, se necesitan condiciones sociales de explotación, miseria y opresión, y que estos grupos no vean ninguna posibilidad objetiva de salir de él, algo que los pentecostales vivieron y experimentaron durante gran parte del siglo XX. En este sentido, la creencia premilenarista subyace en la cultura andina y en los espacios transfronterizos y trasandinos en donde los bolivianos transitan y migran.

\section{EI (pre)milenarismo en la frontera chilena-boliviana}

El premilenarismo es una creencia que brinda consuelo y esperanza a los creyentes indígenas andinos convertidos al adventismo y al pentecostalismo, situados en los espacios fronterizos y que tienen prácticas religiosas transfronterizas. La diferencia entre los premilenarismos de los adventistas y los pentecostales radica en que los primeros se autodefinen como "futuristas históricos" y los segundos son concebidos como "futuristas dispensacionalistas". También hay diferencias en cómo estas comunidades viven su premilenarismo de un lado al otro de la frontera. Del lado de Bolivia, se vive intensamente a través de las prédicas y cantos, por tanto, se trata de un premilenarismo ritualizado. En tanto del lado de Chile las prédicas han disminuido, predominando fundamentalmente el canto; se trataría de un premilenarismo estilizado. Asimismo, la creencia premilenial no solo es una creencia teológica, sino que es transformada en recursos triples: social, político 
y simbólico. Esto rompe con el mito de la huida y el quietismo, y se constituye en una creencia que acciona al creyente no solo hacia la esperanza de la movilidad social, sino hacia la posibilidad del cambio social.

\section{El premilenarismo como recurso social}

Como lo dijimos anteriormente, la creencia premilenarista produce en los grupos religiosos recursos de vida muy significativos, como es la esperanza para sus creyentes. La esperanza "es el más humano de todos los movimientos del ánimo y sólo accesible a los hombres, y está, a la vez, referido al más amplio y el más lúcido de los horizontes, es aquel apetito que nos hace seres insatisfechos" (Bloch, 2004, p. 105). Para Bloch, la esperanza se presenta como un elemento tan importante para el ser humano que lo constituye en un principio de vida; es decir; lo concibe como un aspecto ontológico del ser humano, más importante que la racionalidad del ser cartesiano o la angustia del ser de Heidegger. La esperanza no es solo vida, es un principio ontológico del ser (Bloch, 2004; Desroche, 1976; Fromm, 1970). Este juntarse y reunirse en retiros espirituales en los espacios sagrados para los andinos como los cerros, valles y desiertos, no solo trae memoria étnica, sino que además potencia el sentido comunitario entre los creyentes andinos. Lo último que se puede perder es la esperanza. Mientras haya esperanza de cambio, de transformación, de un mañana mejor, de que los hijos o los nietos disfrutarán los beneficios de los esfuerzos de hoy, entonces vale la pena vivir, vale la pena luchar; porque el vivir es eso: lucha, pena y sacrificio con sentido y significado. Es eso lo que transmiten los premilenaristas y es eso lo que esperan los creyentes.

Como acota Hobsbawm (2003): "la esencia del milenarismo es la esperanza de un cambio completo y radical del mundo, que se reflejará en el milenio, un mundo limpio de todas sus deficiencias presentes, que no queda confinada al primitivismo" (p. 93). Esta creencia milenial es más predicada y está más activa entre los grupos pentecostales y adventistas de Bolivia que de Chile. La idea es que ritos como el ayuno comunitario, las oraciones intercesoras o los retiros en el desierto o en los cerros (espacios sagrados para la 
tradición aymara), pueden apurar la llegada del milenio, de ahí que se intensifique (Albó, 2005; Mansilla, 2016; Rivière, 2004;). En los espacios fronterizos de Chile, estas creencias se vuelven más rutinarias que ritualizadas; se cantan mucho a través de los himnos mileniales, pero se predican muy poco, por tanto los ritos comunitarios son muy poco regulares. Se trata de un milenarismo estilizado, en tanto las creencias son creídas y ritualizadas en los cantos, pero no en las prédicas; es decir, se continúa creyendo, pero "se tiene por tardanza"; se canta al milenio, pero no con la pasión de la inminencia, sino como recuerdo de un pasado comunitario.

De ambos lados se cantan los mismos himnos, obviamente cambian los estilos, las entonaciones, según el contexto cultural. Desde el lado de Chile existen pocos ritos para apurar el milenio, pero desde Bolivia las ritualidades premilenaristas se intensifican los fines de semana y en feriados. 


\section{Cuadro comparativo Himnos Iglesia Adventista y Evangélica Pentecostal}

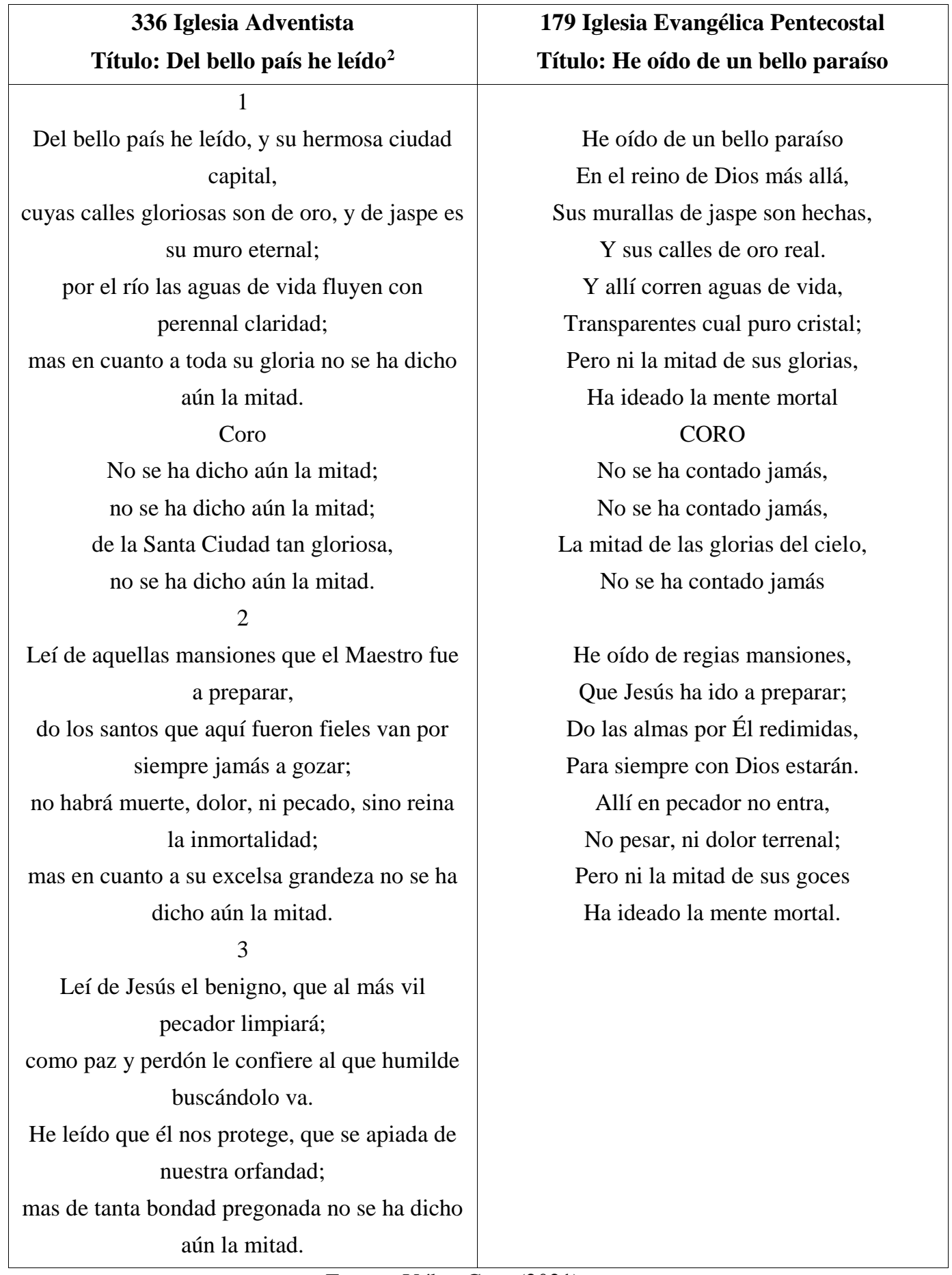

Fuente: Vélez-Caro (2021).

${ }^{2}$ Letra: Franklin E. Belden. Vers. esp: Anónimo. Música: Franklin E. Belden. 
La esperanza milenarista no implica solo ilusión, hay algo de realismo en ella. La vida tal cual se vive es tremenda, difícil de sobrellevar y, por sobre todo, la concepción de que no se puede mejorar ni cambiar (Lanternari, 1965; Pereira de Queiroz, 1978; Worsley, 1980). Tanto adventistas como pentecostales creen y enfatizan que no se puede cambiar la sociedad, pero sí es posible el cambio individual: no es posible cambiar el mundo, pero sí es posible cambiar el mundo interior (D’Epinay, 1968; Tennekes, 1985). Si solo es posible transformar una vida, entonces hay que llevar a cabo todos los ritos que sean posibles, aunque eso implique sacrificios, para cambiar al individuo y atraer más personas al templo para ese cambio interior. Los sacrificios de hoy son las alegrías de mañana. Ambas denominaciones (adventista y pentecostal) rechazan la sociedad, conciben toda actividad política como maligna y ponzoñosa, que mata el espíritu (pneumacidio). La sociedad es irredenta: nada humano la puede cambiar, ni siquiera Dios, solo es posible la debacle por intervención divina, no para redimir, sino para destruir (López, 1990; Ströbele-Gregor, 1989).

Para la conciencia milenarista, el futuro es tan oscuro que hay que recurrir al pasado para transformarlo. Por lo tanto, al igual que en el pasado, los cambios que se produjeron responden a guerras, tribulaciones, pestes y hambrunas; así será el futuro: un doloroso apocalipsis. El desencanto político de los premilenaristas tiene afinidad valórica con el desencanto del converso, quien no ha recibido nada de la política ni de los políticos.

En síntesis, las prácticas sociales que resultan de las creencias premilenaristas incentivan y empujan a las comunidades religiosas a reunirse con mayor frecuencia en distintos espacios y tiempos, en los cuales se potencia y recrea la comunidad étnica, generando distintas posibilidades de apoyo y acompañamiento a los creyentes más precarios y necesitados de la comunidad religiosa. De igual modo, estos tiempos-espacios permiten a los adultos y adultos mayores hablar y cantar en aymara, así como preparar e intercambiar comidas. Generalmente en estos tiempos-espacios rituales se trata además de intercambios de ida y vueltas con congregaciones situadas en los espacios fronterizos, por tanto se trata de prácticas religiosas transfronterizas. 


\section{El premilenarismo como recurso político}

Un segundo recurso que entrega la creencia premilenarista es el sentido de justicia diferida. Los oprimidos, explotados y excluidos socialmente conciben la justicia como algo que beneficia a los poderosos y perjudica a los pobres. En el Estado y la democracia, en la política y los políticos o en la justicia y en los jueces, no hay justicia para el pobre. No obstante, en la creencia premilenarista la justicia diferida refiere a que el mundo se invertirá: "toda lágrima será enjugada" y los pobres no solo nunca más lo serán, sino que además serán ellos lo que gobernarán el mundo, y los que hoy gobiernan serán los gobernados. Será un mundo no gobernado por leyes, sino por la justicia.

La Iglesia Adventista del Séptimo Día sostiene 28 doctrinas fundamentales, las cuales están organizadas en seis doctrinas. En la doctrina número 6, titulada "La Doctrina de los Acontecimientos Finales (23 al 28), la número 27 señala $^{3}$ :

El milenio es el reino de mil años de Cristo con sus santos en el cielo, que se extiende entre la primera y la segunda resurrección. Durante ese tiempo serán juzgados los impíos; la Tierra estará completamente desolada, sin habitantes humanos con vida, pero sí ocupada por Satanás y sus ángeles. Al terminar ese período, Cristo y sus santos, y la Santa Ciudad, descenderán del cielo a la Tierra. Los impíos muertos resucitarán entonces y, junto con Satanás y sus ángeles, rodearán la ciudad, pero el fuego de Dios los consumirá y purificará la Tierra. De ese modo, el universo será librado del pecado y de los pecadores para siempre. (Apocalipsis 20; 21:1$5)$.

La creencia premilenarista fortalece la solidaridad entre la comunidad de elegidos. Pudiese parecer un acto puramente religioso, pero al tener un alto contenido de participación de indígenas se trata de una solidaridad étnica.

Cuanto más cerradas se ven las posibilidades de cambio y transformación social y política, mayores serán las probabilidades de unirse a

\footnotetext{
${ }^{3} \mathrm{Al}$ respecto se puede consultar en la página de la Iglesia Adventista: https://laverdadpresenteiasd.jimdofree.com/28-creencias-de-la-iasd/ 
grupos religiosos que sostengan o resalten creencias milenaristas (Albó, 2005; Barabas, 2002). Sucede que la misma denominación, por ejemplo, la adventista en La Paz u Oruro y en Arica, los énfasis en las prédicas milenaristas varían tal como los himnos milenaristas. Entre las prédicas se destaca:

Hay que notar que a primera vista este capítulo [Cap. 20 de Apocalipsis) no parece describir el regreso de Cristo; en lugar de ello habla de "un ángel que descendía del cielo, con la llave del abismo, y una gran cadena en la mano" (Apocalipsis 20:1). Esto nos hace recordar la primera visión en el Apocalipsis donde "uno semejante al Hijo del Hombre" -sin duda una visión de Cristo mismo- es descrito como "el que vivo, y estuve muerto; mas he aquí que vivo por los siglos de los siglos, amén. Y tengo las llaves de la muerte y del Hades (la tumba)" (Apocalipsis 1:18). ¿Quién otro puede ser ese ángel sino el Señor Jesucristo, "el primogénito de los muertos" (1:5) y por lo tanto a quien Dios ha dado poder sobre la vida y la muerte? (Prédica adventista sobre el milenio, Valle de Azapa, Arica, septiembre de 2019).

Como en toda creencia premilenial no solo se incentiva la creencia y salvación de la comunidad de elegidos, sino también el castigo de los opresores. Se trata de un tiempo y un espacio eterno de inversión social y política, de empoderamiento, en donde los sin poder gobernarán y los poderosos serán gobernados, pero también castigados.

Los adventistas son críticos del premilenarismo dispencionalista de los pentecostales:

Los dispensacionalistas enseñan equivocadamente un arrebatamiento secreto en la venida de Cristo, y que en el milenio todos los judíos se convertirán y volverán a ser el pueblo de Dios. A su vez, los adventistas del séptimo día son premilenaristas bíblicos porque, de acuerdo con las Escrituras, enseñan que la segunda venida de Cristo será un evento único, real, audible, visible, mundial, glorioso, que ocurrirá al comienzo del milenio (Mateo 24). (Prédica adventista, Santa Cruz, Bolivia). 
Tanto adventistas como pentecostales compiten en ganar adeptos entre las comunidades indígenas. En efecto, no solo se presentan a sí mismos como la única religión verdadera, sino que también plantean críticas a la religión con la que compiten. De este modo, es la competencia y no la solidaridad lo que hace crecer a los evangélicos entre las comunidades indígenas, para presentarse a sí mismos como la única y verdadera religión, teniendo como respaldo los números de salvados y congregados.

Lo mismo sucede con la Iglesia Evangélica Pentecostal en Arica, sobre todo en los valles (Azapa, Lluta) y en Colchane (Tarapacá), mientras que en El Alto o en Oruro los énfasis de prédicas y cantos milenaristas son más frecuentes en Bolivia, así como los énfasis rituales con propósito milenario. También hay que destacar que el énfasis milenarista de la Iglesia Evangélica Pentecostal en Chile, hasta la década de 1980, fue muy frecuente (Mansilla, 2014, 2016). Los énfasis desaparecerán o disminuirán por un tiempo, pero florecerán en otro tiempo de crisis, cuando se vuelva a concebir metafóricamente la sociedad como yermo; entonces, llueven los sermones revitalizadores de algún predicador. Ejemplo de lo anterior es cómo ven estos grupos religiosos premilenaristas las protestas sociales de octubre del año 2019 en Bolivia y Chile; cómo ven los premilenaristas la cuarentena y la pandemia, y los cierres de fronteras y de templos, teniendo en consideración que se trata de comunidades étnicas y religiosas tan habituales a las reuniones y encuentros físicos, y tan poco habituales a las reuniones on line, a las "zoomgregaciones", Youtube, o Facebook.

Por otro lado, la Iglesia Evangélica Pentecostal destaca en su prédica:

Cristo volverá secretamente desde los cielos para arrebatar a los santos que aún viven (1. ${ }^{a}$ fase de su Segunda Venida) y resucitar los cuerpos de los santos ya fallecidos (1. ${ }^{a}$ Resurrección). Estos serán sacados del mundo antes de la Gran Tribulación. El juicio de los santos se efectuará en los cielos durante el período de los siete años de Tribulación antes del retorno corporal de Cristo a la Tierra. (Prédica en la Iglesia Evangélica Pentecostal, Oruro, Bolivia). 
Al igual que los adventistas, los pentecostales resaltan sus comunidades de elegidos como los empoderados del milenio, así como también el castigo de los opresores. De este modo, el premilenarismo es presentado como un recurso de justicia simbólica mediante el cual los oprimidos será empoderados y los poderosos se volverán los gobernados sin poder.

Las creencias milenaristas "han aparecido una y otra vez a lo largo de la historia, a pesar de los fracasos, los desengaños y la represión, precisamente porque hacen un llamamiento a los oprimidos, a los desheredados y a los miserables" (Worsley, 1980, p. 313). Los movimientos milenaristas cuando no son hostigados por instituciones eclesiales y políticas son despreciados por los grupos sociales acomodados de la sociedad, y son arrojados a las penumbras de la locura, el fanatismo, o bien, al silencio o invisibilidad de los anales de la historia (Barabas, 2002; Ullán de la Rosa, 2000; Zea, 1986).

Como destacamos anteriormente, la gran diferencia entre los premilenarismos de los adventistas y los pentecostales estriba en que los primero se autodefinen como "futuristas históricos" mientras que los segundos son concebidos como "futuristas dispensacionalistas", porque se autodefinen como "arrebatados" o del "Rapto de la Iglesia". No obstante, ambos son futuristas porque cambiaron el método historicista de los reformadores por el futurismo de la Contrarreforma, y sustituyeron el énfasis en el papado como el anticristo por un individuo futuro que perseguirá a los creyentes (López, 1990; Mansilla, 2012, 2013). Según ambos,

el reino milenario ocurre en la Tierra. A pesar de eso, mientras los premilenaristas históricos consideran a la iglesia el verdadero Israel de Dios, los premilenaristas dispensacionalistas esperan que las profecías del Antiguo Testamento sobre Israel se cumplan con la restauración literal de la nación y de su templo en Jerusalén. (Borba, 4 de abril de 2019, s. p.).

En tanto, el énfasis premileninarista dispensacionalista de los pentecostales se advierte en la siguiente prédica: 
Pero no queremos, hermanos, que ignoréis acerca de los que duermen, para que no os entristezcáis como lo hacen los demás que no tienen esperanza. Porque si creemos que Jesús murió y resucitó, así también Dios traerá con Él a los que durmieron en Jesús. Por lo cual os decimos esto por la palabra del Señor: que nosotros los que estemos vivos que permanezcamos hasta la venida del Señor, no precederemos a los que durmieron. Pues el Señor mismo descenderá del cielo con voz de mando, con voz de arcángel y con la trompeta de Dios, y los muertos en Cristo se levantarán primero. Entonces nosotros, los que estemos vivos que permanezcamos, seremos arrebatados juntamente con ellos en las nubes al encuentro del Señor en el aire, y así estaremos con el Señor siempre. (Prédica en Iglesia Evangélica Pentecostal, Alto La Paz).

\section{El premilenarismo como recurso simbólico}

Por último, quizás uno de los recursos que consuela y trae esperanza es la concepción de la vida como peregrino, la vida como viaje, la vida como pasajero. Las condiciones de vida contribuyen a comprender su fragilidad, fugacidad y frugalidad. Esta concepción de vida ayuda a entender la concepción ontológica del andino, la vida móvil: el ser humano, el andino, es alguien que viaja, que se mueve, que transita de un lado a otro. Las fronteras son solo un obstáculo, una tranca que hay que eludir o pasar, ya sea un cerro o un desierto que hay que cruzar, pero nada ni nadie detiene al andino en su transitar, porque la vida es viaje y el viaje es vida.

Por ello los premilenaristas rechazan todo intento de restringir la religión a reformas sociales y compromisos políticos. Porque la religión está llamada a predicar la salvación del alma, no a salvar la sociedad. Estos son llamados a servir y atender al prójimo, no a luchar ni promover reformas sociopolíticas. El rol de la religión es reformar el alma y no la sociedad. Por un lado, se trata de una visión pesimista, desencantada y trágica de la vida. La meta, no solo no es transformar la sociedad, sino que hay que alejarse y salir del mundo; esto es, el éxodo simbólico: "un morir para el mundo". El creyente es un "homo viator" (Maffesoli, 2005, p. 30) y una memoria recursiva sobre la 
muerte y, por ende, no necesita arraigarse en lo material, sino solo en lo indispensable. El mundo (la sociedad) está "muerto en delitos y pecados" y todas sus actividades son mortíferas: trabajo, alimentación, bebida, vestimenta, festividades, escolarización (Mansilla, 2012, 2013, 2014, 2016). También las instituciones están muertas: política, religión, ciencia y educación, que en vez de darle vida al individuo son pneumacidas.

De igual modo, tampoco la religión premilenarista acepta las presiones sociales, tales como la incorporación de la mujer al liderazgo pastoral, ya que son presiones externas, mundanas y, en el peor de los casos, presiones del feminismo. El feminismo no solo es considerado mundano, sino también demoniaco, en tanto debilita la familia sostenida por la interpretación bíblica de la denominación. La contradicción premilenarista de la Iglesia Evangélica Pentecostal se manifiesta en que pese a creer en el arrebatamiento inminente y desincentivar a que los feligreses opten por la inversión material, por ejemplo, en obtener mejores viviendas, es enfática en construir grandes y nuevos templos.

No se turbe vuestro corazón; creed en Dios, creed también en mí. En la casa de mi Padre hay muchas moradas; si no fuera así, os lo hubiera dicho; porque voy a preparar un lugar para vosotros. Y si me voy y preparo un lugar para vosotros, vendré otra vez y os tomaré conmigo; para que donde yo estoy, estéis también vosotros. (Juan 14:1-3).

Los creyentes premilenaristas no deben preocuparse de las características de sus viviendas, por el contrario, la precariedad les empuja a no arraigarse en el mundo, en tanto esta vida es precaria y fugaz, porque la verdadera vivienda está más allá de este mundo, de esta vida y de esta sociedad.

Y esto digo, hermanos: que la carne y la sangre no pueden heredar el reino de Dios; ni lo que se corrompe hereda lo incorruptible. He aquí, os digo un misterio: no todos dormiremos, pero todos seremos transformados en un momento, en un abrir y cerrar de ojos, a la trompeta final; pues la trompeta sonará y los muertos resucitarán incorruptibles, y nosotros seremos transformados. (1 Corintios 15:50-52). 
Según Stoll (1990), los premilenaristas

siempre han considerado el fin del mundo con un cierto anhelo y además pretenden acelerar su llegada, predicando el evangelio cada día y en cada lugar y en todo momento, para que su testimonio llegue a todos los pueblos; y entonces vendrá el fin. (p. 75).

Para Albó (2005), el pentecostalismo premilenarista está relacionado con la identidad peregrina, que lo liga a la tradición judeocristiana, y que los pentecostales interpretan a través de la lectura literal de la Biblia. Frente a esto el autor señala:

El caso más repetido es el "alistamiento", esto es, la eminente venida de Dios para llevar a todos los congregados al cielo. Se trata solamente de un alistamiento porque Dios puede llegar en cualquier momento, con la muerte y el juicio a cada uno. Pero, en muchos de los congregados esta venida inminente se tomaba, sin duda, como algo verdaderamente real, y pasó a ser uno de los elementos centrales de la convivencia. (p. 263).

La apreciación de Albó responde a lo que observó en una comunidad indígena boliviana en la década de 1980. Ahí pudo constatar una creencia y práctica absoluta del premilenarismo: los indígenas se vieron coaccionados a deshacerse y vender todos sus escasos bienes, porque en unos pocos días sucedería el inminente premilenarismo. Lo que ocurrió, sin embargo, fue un eminente fracaso.

En la misma línea, Rivière (1988) destaca que la identidad del pentecostalismo se ve reforzada por una certeza compartida: la inminencia del fin de los tiempos. La espera sigue básicamente el modelo de la escatología pentecostal, que concede una importancia muy grande al milenarismo y a la espera mesiánica. Los pastores comentan constantemente los versículos de la Biblia que mencionan los signos que anuncian el fin de los tiempos y que cualquier persona puede experimentar en la vida cotidiana: terremotos, malas cosechas, sequías, disputas y divisiones (Rivière, 1988). Aquí hay dos supuestos que tampoco desarrolla este autor, pero que sí los vemos a través de 
los conceptos destacados por Kermode (2002, p. 33): primero, "la inminencia premilenial" y la "inmanencia premilenial", y un segundo supuesto, que es la ligazón del premilenio pentecostal con el mesianismo destacado por Robins (1997) y Turner (1988), tales como los ritos mesiánicos vinculados a una muerte simbólica, en tanto se muere para este mundo, para la sociedad, y se vive pensando en el milenio, se vive las virtudes del milenio, los ritos mileniales, los cantos mileniales. El creyente es un sujeto pasajero y móvil que debe estar preparado y presto para el viaje: porque la vida es un viaje, implica ser un migrante en esta tierra, porque la verdadera ciudadanía del creyente está en el otro mundo.

Por último, Marzal (1989), refiriéndose al pentecostalismo peruano, destaca que "el énfasis de un escatalogismo inminente conduce a cierta revitalización de la tarea de transformar el mundo, debido a la concepción insistente de la malignidad del mundo" (p. 427).

En consecuencia, así como Turner (1988) expone un sinnúmero de características que describen el milenarismo, también las encontramos entre los adventistas y pentecostales, cuando este autor destaca que "los movimientos milenaristas surgen entre las masas desarraigadas y desesperadas de la ciudad y el campo, empujadas a vivir en los márgenes de las ciudades" (Turner, 1988, p. 118). Resulta, entonces, que el milenarismo es una ideología plástica y flexible, aplicable a distintas creencias y contextos culturales e históricos. Dada esta plasticidad es que el milenarismo puede ser parte tanto de los adventistas (protestantes misioneros) como de los pentecostales en el contexto andino transfronterizo (Chile, Bolivia y Perú), o de los pentecostales creyentes que transitan entre Bolivia (La Paz, Ciudad de El Alto, Santa Cruz u Oruro) y Chile (Arica, Putre, Colchane) o viceversa.

La concepción milenarista implica una doble concepción de la historia: una historia mitologizada y una mitología histórica. Esto conlleva que los relatos creacionales, las épocas doradas, las intervenciones divinas en la decadencia de los imperios, la redención de los oprimidos y los milagros de sanidades, señalados en la Biblia, son considerados como verdades históricas 
que pueden suceder en distintos momentos históricos. Así, la Biblia es vista como un libro histórico. El Apocalipsis, la Segunda Venida de Cristo, son asimilados como acontecimientos redentores, como promesas reales que emergen ante cada catástrofe, crisis económica, amenazas de guerras, terremotos o hambrunas en alguna región del mundo.

\section{Conclusiones}

El premilenarismo proporciona consuelo y esperanza, en tanto es la consecución de una comunidad de redimidos que se presenta como una alternativa, pero a la vez como un proyecto del devenir histórico prometido (Albó, 2005; Mansilla, 2012; Rivière, 2004; Ströbele-Gregor, 1989). Esto no significa pasividad; hay actividad en los ritos, en los cambios de vida, en los testimonios y en las creencias de bienestar divino, que luego se transforman en libación del presente para una promesa por venir. Pero el milenio hay que comenzar a vivirlo, experimentándolo en el aquí y en el ahora, y hay que predicarlo. Desde la Biblia, Dios es presentado como un Dios del consuelo: "el cual nos consuela en toda tribulación nuestra, para que nosotros podamos consolar a los que están en cualquier aflicción con el consuelo con que nosotros mismos somos consolados por Dios" (2 Corintios 1:4); Dios es "Padre de misericordias y Dios de toda consolación” (2 Corintios 1:3). También Dios es presentado como el Dios de la esperanza: “que el Dios de la esperanza los llene de toda alegría y paz a ustedes que creen en él, para que rebosen de esperanza por el poder del Espíritu Santo" (Romanos 15:13); “Tú eres mi Dios y Salvador; ¡en ti pongo mi esperanza todo el día!” (Salmo 25:13). Estos textos bíblicos son leídos, citados, aprendidos y cantados.

No obstante, los grupos religiosos premilenaristas difícilmente resisten la prueba del tiempo. El Reino se hace esperar y no queda más remedio que instalarse en una provisionalidad que se prolonga. Únicamente la expansión continua, la llegada permanente de conversos para los que la espera no hace sino empezar, es capaz de mantener la esperanza premilenial (D`Epinay, 1983). 
Esto es corroborado por Rivière (2004) en su experiencia con el pentecostalismo indígena boliviano: "la espera mesiánica sigue siendo importante, pero se ha moderado: en lo sucesivo es necesario resolver problemas inmediatos y a menudo con la colaboración de los "paganos", (Rivière, 2004, p. 280). Las revitalizaciones milenaristas siempre tienen que ver con la temporalidad: la nostalgia, la crisis y el anhelo. Ante las crisis económicas, sociales y políticas, sin posibilidades de resolución, toman nuevo significado y se mitifican lugares foráneos como espacios-tiempos perfectos de igualdad, hermandad, abundancia y paz, pero que solo se podrán realizar en el futuro, ya que faltan los recursos materiales para sacudirse el yugo de esclavitud. Por lo tanto, solo una divinidad amiga de los oprimidos los liberará y los llevará a vivir en aquellos tiempos perfectos y castigará a los opresores arrojándolos a la ignominia eterna.

Las creencias milenarias -y mesiánicas- en los Andes han estado desde siempre. López-Baralt (1989) lo resume de manera ilustrada y conmovedora al decir:

¿Cómo extrañarnos que estas nuevas mutaciones del mesianismo [y el milenarismo] vuelvan a ser el motor más recóndito para curar las injusticias de ser extranjeros y despreciados en su propia tierra y el dolor de no ser sí mismos: la aculturación? ¿Con qué cara reprocharle al vencido de la Conquista que la metáfora esté pasando, transgrediéndola, a la literalidad de los nuevos movimientos sociales? ¿Con qué derecho criticar, ridiculizar o satanizar sus esperanzas restauradoras de Orden propio? ¿Volverán las huacas a recuperar el mundo? (p. X).

Los andinos que transitan por las fronteras chileno-bolivianas son los vencidos de siempre, los que han recibido la derrota como herencia. Son como los despreciados y los humillados de la Tierra. Son aquellos que recibieron como herencia la desherencia. Sin embargo, no se sienten víctimas, sino rebeldes. Son seres resistentes que se niegan a perder la esperanza de que sus vidas puedan cambiar y ser transformadas. Insisten en creer en un mundo mejor, en otra vida mejor, y esa esperanza la encuentran en el premilenarismo 
adventista y pentecostal. En ese sentido, la religión no es como la describía Freud (1999): "la imposición de un camino único para alcanzar la felicidad y evitar el sufrimiento" (p. 45), sino más bien, en tanto el sufrimiento es insoslayable para el ser humano. En efecto, lo que la religión hace es resignificar el sufrimiento. Las creencias y ritos religiosos no son para evitar el sufrimiento, sino para hacerlos soportables, llevaderos y significativos.

\section{Referencias bibliográficas}

Albó, X. (2005). ¡Ofadifá Ofadifá! Un pentecostés chiriguano. En B. Guerrero (ed.), De indio a hermano. Pentecostalismo indígena en América Latina (pp. 231-328). Iquique, Chile: Ediciones CAMPVS.

Balandier, G. (1990). Los movimientos de innovación religiosa en el África negra. En H. CH-Puesch (dir.), Movimientos religiosos derivados de la aculturación (pp. 312-351). México: Siglo XXI.

Barabas, A. (2002). Utopías indias. Movimientos sociorreligiosos en México. México: Ed. Plaza y Valdés-INAH.

Bastide, R. (1973). El prójimo y el extraño. El encuentro de las civilizaciones. Buenos Aires: Amorortu.

Bloch, E. (2004). El principio de la Esperanza. Vol. I. Madrid: Editorial Trotta. Borba, W. (4 de abril de 2019). ¿Qué enseña la Biblia sobre el milenio? Sección Sola Escritura. Noticias - Adventistas [En línea]. Recuperado de https://noticias.adventistas.org/es/columna/wilson-borba/que-ensena-labiblia-sobre-el-milenio/

Bou, L. (1997). El milenio termina otra vez, las nuevas religiones de pobres en la periferia de Rosario. En A. Firpo (comp.), Nuestra pobreza (pp. 7176). Rosario, Argentina: Ross.

Cohn, N. (1997). En pos del Milenio. Revolucionarios milenaristas y anarquistas místicos de la Edad Media. Madrid: Alianza Editorial.

D’ Epinay, Ch. (1968). El refugio de las masas: estudio sociológico del protestantismo chileno. Santiago: Editorial Pacifico. 
De la Torre, A. (2004). Movimientos milenaristas y cultos de crisis en el Perú. Análisis histórico y etnológico. Lima: Editorial Fondo P. Universidad Católica.

Desroche, E. (1976). Sociología de la esperanza. Madrid. Herder.

Foerster, R. (1993). Introducción a la religiosidad mapuche. Santiago: Editorial Universitaria.

Freire, P. (1992). La pedagogía de la esperanza. Un encuentro con la pedagogía del oprimido. México: Siglo XXI.

Freud, S. (1999). El porvenir de una ilusión. Obras Completas. Buenos Aires: Amorrortu.

Frigerio, A. (2000). Apocalipsis de papel: el milenio en los medios de comunicación de Argentina. X Jornadas sobre Alternativas Religiosas en Latinoamérica, Buenos Aires, 3-6 de octubre. [Recuperado el 12 de octubre de 2008]. http://www.naya.org.ar/religion/XJornadas/pdf/8/8Frigerio.PDF

Fromm, E. (1970). La revolución de la esperanza. Hacia una tecnología humanizada. [En línea]. Omegalfa Biblioteca Libre. [Recuperado el 12 de junio de 2012]. https://omegalfa.es/autores.php?letra=\&pagina=9\#

Góngora, M. (1980). Estudios de historia de las ideas y de historia social. Valparaíso: Editorial Universitaria.

Harris, M. (1999). Vacas, cerdos, guerras y brujas. Madrid: Alianza editorial.

Hobsbawm, E. (2003). Rebeldes primitivos. Estudio sobre las formas arcaicas de los movimientos sociales en los siglos XIX y XX. Barcelona: Editorial Ariel.

Izcara, P. (2007). Privación relativa y emigración: el caso tamaulipeco. Revista Migraciones Internacionales, 5(1), 7-33.

Kermode, F. (2002). El sentido de un final. Estudios sobre la teoría de la ficción. Trad. Lucrecia Moreno de Sáenz. Barcelona: Editorial Gedisa.

Kumar, K. (2000). El apocalipsis, el milenio y la utopía en la actualidad. En M. Bull (comp.), Teoría del Apocalipsis y los fines del mundo (pp. 233260). México: Fondo de Cultura Económica.

La Biblia (1960). Reina Valera. Pekín: Editorial Vida. 
Lanternari, V. (1965). Movimientos religiosos de libertad y salvación de los pueblos oprimidos. Barcelona: Seix Barral.

López, E. (1990). Pentecostalismo y milenarismo. La Iglesia apostólica de la fe en Cristo Jesús. México: Universidad Autónoma Metropolitana.

López-Baralt, M. (1989). El retorno del Inca Rey. Mito y profecía en el mundo andino. La Paz: Hisbol.

Lynch, J. (2001). Masacre en las Pampas: la matanza de inmigrantes en Tandil, 1872. Buenos Aires: Editorial Emecé.

Macagno, L. (2002). Apocalipsis al sur: una protesta contra inmigrantes en el "desierto" argentino. Buenos Aires: Editorial Biblos.

Maffesoli, M. (2005). El nomadismo. Vagabundeos iniciáticos. México: Fondo de Cultura Económica.

Mansilla, M. (2012). Muerte, esperanza y protesta en el pentecostalismo chileno. Las representaciones del cielo en la Iglesia Evangélica Pentecostal de Chile. Revista Sociedad y Religión, 22(37), 123-166.

Mansilla, M. (2013). Entre la nostalgia y el sueño de la igualdad. Crítica y propuesta a los supuestos fundacionalistas de la comunidad pentecostal en Lalive d'Espinay. Revista Polis, 13(37), 407-430.

Mansilla, M. (2014). La cruz y la esperanza. La cultura del pentecostalismo chileno en la primera mitad del siglo XX. México: MANDA, CIALUNAM, UNAP.

Mansilla, M. (2016). La buena muerte. La cultura del morir en el Pentecostalismo. Santiago: UNAP-RIL.

Martínez, F. (1990). Milenarismo y defensa de la fe en el Siglo de las Luces: la obra del jesuita chileno Miguel Lacunza. Revista Historia Crítica, (3), 45-67.

Marzal, M. (1989). Los caminos religiosos de los inmigrantes en la Gran Lima. El caso del Agustino. Lima: Fondo Editorial Universidad Católica.

Meliá, B. (1991). La experiencia religiosa guaraní. En M. Marzal, R. Robles, E. Maurer, X. Albó y B. Meliá, Rostros indios de Dios. Los amerindios cristianos (pp. 267-322). Quito: Edición Abya- Yala. 
Monsiváis, C. (1986). De los milenarismos desautorizados. En J. Cabayet (comp.), Hacia el Nuevo Milenio. Estudios sobre mesianismos, identidad nacional y socialismo. Utopía, nacionalismo y socialismo. Vol. II (pp. 211-226). México: Editorial Villicaña.

Morales, M. (1980). Milenarismo. Mito y realidad del fin de los tiempos. Barcelona:Editorial Gedisa.

Osorio, O. (2004). La iglesia de los testigos de Jehová en el fin de todos los tiempos. Discurso escatológico y milenarista en Los Altos Centrales de Morelos, México. Ponencias presentadas en el XI International Summer School on Religions en la comunidad de San Gimignano, Siena, 24 de agosto, Universidad Autónoma de México, Iztapalapa, México DF.

Parra, F. (2003). Historia y escatología en Manuel Lacunza. Revista Teología y Vida, 44 (2-3), 167-168.

Pereira de Queiroz, M. (1978). Historia y etnología de los movimientos mesiánicos. Madrid: Siglo XXI,

Rivière, G. (1988). Cambios sociales y pentecostalismo en una comunidad Aymara. Revista Fe y Pueblo. Centro de Teología Popular de La Paz, 3, 24-30.

Rivière, G. (2004). Bolivia: el pentecostalismo en la sociedad aimara del Altiplano. En A. Spedding (comp.), Gracias a Dios y a los achachilas. Ensayos de sociología de la religión en los Andes (pp. 259-294). La Paz: ISEAT-PLURAL.

Robins, N. (1997). El mesianismo y la rebelión indígena. La rebelión de Oruro en 1781. La Paz: Editorial Hisbol.

Rojas, M. (2001). El fin del Milenio y el sentido de la historia. Manuel Lacunza y Juan Ignacio Molina. Editorial Lom. Santiago de Chile.

Schäfer, H. (1992). Protestantismo y crisis social en América Central. San José: Editorial DEI.

Stoll, D. (1990). ¿América Latina se vuelve protestante? Las políticas del crecimiento evangélico. Quito: Editorial Abaya-Yala. 
Ströbele-Gregor, J. (1989). Indios de piel blanca. Evangelistas fundamentalistas en Chuquiyawu. La Paz: Editorial Hisbol.

Tennekes, H. (1985). El movimiento pentecostal en la sociedad chilena. Amsterdam/Iquique. Chile: Centro de Investigación de la Realidad del Norte (Ciren) y Subfacultad de Antropología Cultural y Sociología No Occidental de la Universidad Libre de Ámsterdam.

Terán, B. (2000). El pentecostalismo y las culturas tradicionales. Revista Cultural Casa Tomada. Rosario, Argentina: Ediciones Juglaría. Recuperado de http://edicionesjuglaria.com.ar/seccionC/archivos casatomada/terancasa1.htm

Turner, V. (1988). El proceso ritual. Madrid: Editorial Taurus.

Ullán de la Rosa, F. (2000). Plurimorfología del fenómeno mesiánicomilenarista: la secuencia histórica de los movimientos ticuna. Estudio del Hombre, (11), 13-40.

Vélez-Caro, C. (2021). Cantando en la frontera. Música e imágenes premileniaristas en el espacio fronterizo andino de Chile con Bolivia en las iglesias adventista y pentecostal. En M. Mansilla (comp.), La fe mueve fronteras. Evangélicos en espacios fronterizos chilenos $y$ bolivianos (pp107-139). Santiago: RIL Editores.

Vergara, J., Foerster, R. y Gundermann, H. (2005). Instituciones mediadoras, legislación y movimiento indígena de DASIN a CONADI (1953-1994). Atenea (Concepción) [en línea], (491), 71-85. http://dx.doi.org/10.4067/S0049-34492003000200003

Watson, F., Corry, S. y Pearce, C. (2000). Los desheredados. Indígenas de Brasil. Barcelona: Survival.

Worsley, P. (1980). Al son de la trompeta final. Un estudio de los cultos "cargo" en Melanesia. Madrid: Siglo XXI.

Zea, L. (1986). Latinoamérica, milenarismo en la utopía. En J. Cabayet (comp.), Hacia el Nuevo Milenio. Estudios sobre mesianismos, identidad nacional y socialismo. Utopía, nacionalismo y socialismo. Vol. II (pp. 35-58). México: Editorial Villicaña. 
** Sociólogo. Doctor en Antropología. Académico e investigador del Instituto de Estudios Internacionales (INTE) de la Universidad Arturo Prat, Chile. Especialista en estudios sobre el pentecostalismo y el protestantismo. Sus investigaciones han estado centradas en la frontera norte de Chile con Bolivia y Perú. mansilla.miguel@gmail.com

${ }^{* * *}$ Socióloga, Pontificia Universidad Católica de Chile. Doctora en Sociología, Georg-AugustUniversität Göttingen, Alemania. Profesora titular e investigadora del Instituto de Estudios Internacionales (INTE) de la Universidad Arturo Prat, Chile. Estudia temas como migración, cuidados, género y trabajo. sandraleiva@gmail.com

Mansilla, M. y Leiva, S. (2021). Antropología del milenarismo: el premilenarismo entre adventistas y pentecostales en los espacios fronterizos chileno-bolivianos. Revista Cultura \& Religión, 15 (1), 330-369. 